\title{
Bachelard, Cassirer and Early Interdisciplinary Humanities
}

\author{
Maria-Ana Tupan \\ Prof. Dr. Habil., Philology, Doctoral School, Department of Philology and History, Alba Iulia \\ University, Alba Iulia, Romania. Email:m_tupan@yahoo.com
}

Received November 19, 2016; Revised December 15, 2016; Accepted December 30, 2016; Published January 14, 2017

\begin{abstract}
Interdisciplinarity is "the ideal entry point into one of today's most heated critical debates" reads the back blurb of the book published by Joe Moran at the beginning of the twenty-first century (Routledge, 2002). How old was actually the "New Critical Idiom" in the philosophy of cultural representation is the question the present paper is trying to answer. We are travelling back in time to the point where aesthetics, poetics or art theory extended to include domains that Immanuel Kant had placed on the other side of the disciplinary divide: physics, algebra, geometry. The rise of a meta theory for disciplinary interfaces is related to the writings of Gaston Bachelard and Ernst Cassirer, who were sensitive to radical shifts in contemporary thought: the former responded to the rise of postformal thought (the logique du contradictoire, or polyvalent logic, informing the quantum superposition of states), while the latter took over from Felix Klein's invariant theory the model of a unified frame for symbolic representation which rendered possible correlations across disciplinary fields and the coming together of the multiple languages of mythology, religion, science and art.
\end{abstract}

Keywords: Interdisciplinarity, the New Critical Idiom, cultural representation, disciplinary reconfiguration, postformal thought.

Not less than four modal expressions of normativity were used by David Bartholomae, Associate Professor of English and Director of Composition at the University of Pittsburgh, at the height of what had come to be called the "terror of theory" in the ninth decade of the last century:

The students have to appropriate (or be appropriated by) a specialized discourse, and they have to do this as though they were easily and comfortably one with their audience, as though they were members of the academy, or historians or anthropologists or economists; they have to invent the university by assembling and mimicking its language, finding some compromise between idiosyncracy, a personal history, and the requirements of convention, the history of a discipline. They must learn to speak our language (Bartholomae: web).

From a high landing, the site of academic humanities looks nowadays like the famous "Querelle des Anciens et des Modernes" in the dawns of modernity, the combatants being distributed along the frontline separating pro-theorists from anti-theorists. Looking backward at my own career as student, I come to two contradictory conclusions: on the one hand, that several authors who were then enshrined in the canon (Malcolm Lowry, Lawrence Durrell, Iris Murdoch, among others) enjoy little attention from professional critics nowadays, while others who were not studied at all

(C) AesthetixMS 2016. This Open Access article is published under a Creative Commons Attribution Non-Commercial 4.0 International License (http://creativecommons.org/licenses/by-nc/4.o/), which permits non-commercial re-use, distribution, and reproduction in any medium, provided the original work is properly cited. For citation use the DOI. For commercial re-use, please contact editor@rupkatha.com. 
are now assiduously being searched (J.L. Borges, John Fowles, Flann O’Brien ...). The fact might seem to speak against formal education, but, on the other hand, it is the institutionalized studies of literature that have tilted the balance in favour of texts supportive of theorized approaches fuelled by new concepts, such as deconstruction of history, world building, parallel worlds, selfreflexivity, metafiction, rewriting, hypertexts, etc. Multiple narratives of the same events from different points of view, as in The Alexandria Quartet, has in the meantime been reclassified as modernist phenomenology of perception, a throwback in comparison to parallel epic trajectories of a fictional multiverse, as in Borges's "The Garden of Forking Paths", flourishing upon New Physics speculations and underwriting the shift to postmodernist phenomenology of textuality. Changes in epistemology are now seen to bring about changes in poetics, building a bridge over the gulf which C.P. Snow had deemed to exist between "the two cultures", i.e., science and the humanities. The study of literature has practically vanished from the curriculum, being first replaced with Literary Studies, subsequently with Cultural Studies, and finally included under the broad heading of "Humanities".

The latest buzz is interdisciplinarity, studies that cut across disciplinary boundaries, including the last stronghold of science versus humanities. "As custodians of literary knowledge', Sowon S. Park writes trying to unriddle “The Dilemma of Cognitive Literary Studies" (Park: 78), 'humanists bear some responsibility for making accessible the rich observations of human mind to scientific research. The translation of literary terms into cognitive terms and vice versa, which is one of the primary activities of cognitive literary criticism, render a valuable service to the course of consilience by opening up the possibility of the two cultures talking to one another."

The paradoxical outcome of this evolution, but at the same time a proof of its effectiveness, is the unprecedented discontinuity of late modernity from the unified picture of the former history of the arts: whereas the classical age, the Middle Ages, the Renaissance, neoclassicism or romanticism had been informed by a unified epistemology (world picture) and poetics, modernism displays such a motley picture as to allow Peter Nicholls to speak of it in the plural (Peter Nicholls, Modernisms, 1995). At a closer look, the heterogeneous threads seem to recede into the background, whose diagonal splits a poetics of invariants from a quantum field of heretic behaviour. In music, neoclassicism coexists with the Vienna dodecaphonism; in the arts, the North of London modernism pitied against the South (Italy and France) of Futurism struck Wyndham Lewis and his coterie gathered around The Blast as the discrepancy between two distinct races, with Vorticists hunting down the machines whose Romance Marinetti was extolling (“Automobilism”, 1914). Impressionism yielded to expressionism (around 1911) and the latter to Magic Realism (1925) through revolutions that each time left behind scorched ground. A contemporary of these aesthetic mutations, Nobel Award winner Werner Heisenberg put change in styles to the door of epistemology in his book Physics and Philosophy (1958):

[...] are the different styles of art an arbitrary product of the human mind? Here again we must not be misled by the Cartesian Partition. The style arises out of the interplay between the world and ourselves, or more specifically between the spirit of the time

and the artist. The spirit of a time is probably a fact as objective as any fact in natural science, and this spirit brings out certain features of the world which are even independent of time, are in this sense eternal. The artist tries by his work to make these

features understandable, and in this attempt he is led to the forms of the style in which he works (Heisenberg: 98). 
It was only that epistemology was no longer unified. The evolution from classical physics to the physics of relativity and the quantum revolution gave birth to contradictory epistemologies: on the one hand, there was a search for invariants, whether physical, such as the speed of light (and all laws of Physics, according to Einstein) under a Lorentz transformation, or abstract (Klein's Erlangen Programme (properties that remain invariant under homeomorphism). On the other hand, the rise of quantum physics brought in its train a world of "wild surmise", but still more disquieting than those imagined by John Keats to have filled explorer Cortez when he stared at the Pacific "upon a peak in Darien" (On First Looking into Chapman's Homer). It was a picture of unpredictable transformations, of permanent emergence, of superposition of contrary states, unfathomable so as to render measurements uncertain and untouchable, in the sense that those measurements changed the state of the system, and therefore could not be said to state anything stable about its nature. Theory, they say, is the creation of the last generation. Postwar schools of studies in literature moved outside its boundaries, exploring relevant information and methods in extra-literary fields, such as psychoanalysis, sociology, history, or philosophy of language, combining them, creating hybrid disciplines, such as cultural studies, identity studies, gender studies, postcolonial studies, diaspora studies, spatial criticism, etc., ending up in interdisciplinary studies and in integrated educational models, but the beginning had already been done back then, in the earlier twentieth century that had seen the birth of New Physics. All of a sudden we see philosophers of culture and aestheticians taking a fascinated interest in the new developments of science. Less famous than Nietzsche's decree of the "death of God", Martin Heidegger's insightful comment on the death of the erudite scholar who was being replaced by the researcher possessed of a project, journeying from one conference to another, focusing on themes chosen in common with the community of discourse and publishing, was proof of his awareness of a phenomenon that Thomas Carlyle had in vain tried to resist in the previous century ("Signs of the Times"): the institutionalization of science, its essence as the priority of method over the object of investigation ("The Age of the World Picture"):

The scholar disappears. He is succeeded by the research man who is engaged in research projects. These, rather than the cultivating of erudition, lend to his work its atmosphere of incisiveness. The research man no longer needs a library at home. Moreover, he is constantly on the move. He negotiates at meetings and collects information at congresses. He contracts for commissions with publishers. The latter now determine along with him which books must be written (Heidegger: 77-78)

There was a compensation for the liberal scholar's freedom of choice of subject and treatment: institutionalized research implied the search for rules of change, and, if changes were constant, the discovery of laws governing those changes. The new technology of research was no longer limited to the description of the object, it cast about for explanations in light of a methodology rising above nature and history; it aspired to accountability in its reconstruction of the object according to its ontology:

What is taking place in this extending and consolidating of the institutional character of the sciences? Nothing less than the making secure of the precedence of methodology over whatever is (nature and history), which at any given time becomes objective

in research. On the foundation of their character as ongoing activity, the sciences are creating for themselves the solidarity and unity appropriate to them. Therefore historiographical or archeological research that is carried forward in an institutionalized 
way is essentially closer to research in physics that is similarly organized than it is to a discipline belonging to its own faculty in the humanistic sciences that still remains mired in mere erudition (Ibid.).

Standing at the crossroads of the new search for universals and the plumbing of the enigmatic quantum abyss, Ernst Cassirer and Gaston Bachelard set the cornerstone of interdisciplinarity, embedding their reflections on aesthetic objects in the epistemological frames of contemporary science. Both of them aspired to an extended epistemology, both of them appealed to a unified matrix of cognition built by various disciplines, but whereas Cassirer continued to recognize the "specificity and independence" of each of them, proposing a functional unity whereby their diversity would "complement and further one another" (Cassirer: web), Bachelard affiliated himself with schola quantorum, reinforcing in aesthetic perception and poetics its non-Cartesian epistemology and its metaphysique du contradictoire, that is, showing his disposition to work with polyvalent logics (Bachelard: 17).

Cassirer's search for invariance brought him close to Klein: "In an article published one year before his death, Cassirer shows that perception and Klein's geometry have many features in common, e.g., transformation, invariance, choice of the geometry (Euclidean, affine, projective, etc.)" (Wildgen: 15/22). He tried to apply the formal languages of science to language, myth, religion, art, but he did not go so far as to use them indiscriminately: "mathematical concepts [applied] to the natural sciences are no guarantee that they can be applied to the parallel symbolic forms" (Ibid.).

In his attempt to bridge mundus sensibilis and mundus intelligibilis, Ernst Cassirer was walking in Wilhelm Wundt's shoes, who had claimed before him to have surpassed the traditional dilemma of empiricism versus metaphysics by showing them united in the phenomenology of perception, which fused the physical and the psychological "Bild" (picture). Cassirer speaks of image-worlds, and it is impossible for us to read his definition of symbolic forms without recollecting either Joyce's epiphany and Pound's image, or Eliot's objective correlative: "universal formula (combination of universal and specific signs" (Cassirer 78-87) are reached through perception, which is not a mere copy of the sensuous object but also an expression of a force within the spirit: "sense and spirit united in a new form of reciprocity and correlation" [...] progress "from sensation to intuition and ideas". Using symbolic forms as its medium, art is no longer either "expression of inner life or reflection of the forms of outward reality but "a world of representations" (90), fusion of the subjective and the objective.

Cassirer's image-worlds are lying behind post-war elaborations in cognitive linguistics (George Lakoff and Mark Turner), and it is certainly a philosophy of invariants that informs the extensive practice of rewriting in so much of postmodernist fiction. The reification of subjectivity in the symbolic order of society is Karl Popper's third ontological order, adding up to the traditional physical and subjective/metaphysical ones (Objective Knowledge, 1972), and it is this intersubjective order of socially ratified values that French psychoanalists Jacques Lacan ("Law of the Father") and René Girard ("mimetic desire") appeal to in order to explain the workings of the human mind. Inbetween them and Freud, there was Cassirer's deconstruction of the Ego as an individual entity: "Cassirer tends to decentralize the Ego and to conceive of symbolic objectivation, which is rather constitutive for the culture in which Ego lives" (Wildgen: 11/22).

At the other end from invariant psychology, poststructuralism postulated endless deferral of meaning, semiotic transfer, open exchange of semiotic energies, not only in the world of discourses but also between world and texts. In his groundbreaking Mythologies (1957), Roland Barthes acknowledged his debt to Bachelard's poetics of the elements published in the previous 
century, but the latter's Poetics of Space (1958), rooted in theories of the flux of matter and energy, can also be seen as an early adumbration of the holist ontologies of Gilles Deleuze and Francisco Varela.

Postmodernist holism had actually begun decades before, with the attempt to do away with the dividing line between subjectivity and objectivity (Cassirer), between realism and empiricism (Bachelard). The vacilation between prolixité externe (external prolixity) and unité intime (inner unity) (Bachelard 1934: 18) was put to rest in the quantum notion of wave function, subsuming the concept of inner coherence (entanglement of all possible states of a system) as well as the phenomenal, realized, collapsed Eigenstates. Bachelard singled out the fundamental mutations effected by microphysics in the epistemology of classical physics: the principle of complementarity or the superposition of contrary states, which dismissed the logic of identity that had already been destabilized by the birth of non-Euclidian geometry: "la naissance de la géomé-trie non-euclidienne [...] a été la première occasion de la diversification des axiomatiques" (Bachelard: 35). He was absolutely fascinated by the Copernican turn that made cognition dependent upon method and experimental conditions and equipment. By interfering with a system while measuring its state, the equipment changes that state: "les partisans de Heisenberg feront remarquer que la recherche d'un objet minuscule est une expérience délicate et que cette expérience, dès qu'elle est précise, déplace l'objet, dès qu'il est fin. L'expérience fait donc corps avec la définition de l'Être" (Bachelard: 39). Barthes's birth of the reader may be seen as an elaboration upon this theory that a text is but a mute score before the reader "performs" or interprets it. Each interpretation, even by the same reader, is a new, different realization of the text's potential of meaning structures. The idea that the object interferes with the method explains the unprecedented theoretical bloom of the latter half of the $20^{\text {th }}$ century, the commonly felt need for legitimating narratives: "En micro-physique, il n'y a donc pas de méthode d'observation sans action des procédés de la méthode sur l'objet observé. Il y a donc une interférence essentielle de la méthode et de l'objet" (Bachelard : 95). New critical kinds were born: the case studies, the theory readers, the theory into practice collections of essays, probing the interpretative potential of various schools of critical thinking or their comparative efficiency in casting a new light upon canonical texts.

It was not only philosophers or artists who turned to science for simulation models of their systems or fictional worlds, but scientists too contributed to the present-day holistic mental make-up by direct loans from or transformations of matters from extra-disciplinary fields. New Historicism drew on deconstructionist philosophy and narrative theory; psychoanalysts used fictional characters along with real-life patients; the pioneers of quantum physics acknowledged a debt to Hindu philosophy. Bohr and Schrödinger are often quoted on their glosses of Vedic texts (See "Did the Vedic Philosophy Influence the Concept of Free Energy and Quantum Mechanics?" https://www.scienceandnonduality.com/did-the-vedic-philosophy-influenced-the-concept-offree-energy-and-quantum-mechanics/).

It certainly seems strange that the rise of quantum physics, which revised the picture of the classical world completely, should have been perceived by Schrödinger less as a novelty than as the fulfilment of a forefather's dream, spotted out in the descent of the Eastern rather than Western tradition of thought:

We have inherited from our forefathers the keen longing for unified, all-embracing knowledge. We feel clearly that we are only now beginning to acquire reliable material for welding together the sum total of all that is known into a whole; [...] The earliest records to my knowledge date back some 2,500 years or more. From the early great Upanishads 
the recognition ATHMAN = BRAHMAN upheld in (the personal self equals the omnipresent, all-comprehending eternal self) was in Indian thought considered, far from being blasphemous, to represent the quintessence of deepest insight into the happenings of the world. The striving of all the scholars of Vedanta was, after having learnt to pronounce with their lips, really to assimilate in their minds this grandest of all thoughts. Again, the mystics of many centuries, independently, yet in perfect harmony with each other (somewhat like the particles in an ideal gas) have described, each of them, the unique experience of his or her life in terms that can be condensed in the phrase: DEUS FACTUS SUM (I have become God). To Western ideology the thought has remained a stranger, in spite of Schopenhauer and others who stood for it [...] (Schrodinger: web).

One could say that it was the new idiom of relativity and quantum physics that the paradoxes of Hindu cosmogony could be translated into and rendered intelligible in the West. The all-embracing, self-originating, self-sustaining and emergent one, "born of the power of heat" described in the Nasadiva Sukta of Rig Veda is a superposition of states: not the non-existent. The String Theory replaced the dimensionless point of the Bing Bang with a one-dimensional string that seemed to stretch "chords across the void" to bridge non-existence and existence. Even more familiar is the language of sceptic Nagarjuna (c. 150-c. 250), "the second Buddha" of the Tibetan and East Asian Mahayana (Great Vehicle) traditions of Buddhism, who rejected the Brahminical and Buddhist philosophy of stable essences and substantial categories. His concept of the emptiness (sunyata) of all things in Fundamental Verses on the Middle Way (Mulamadhyamakakarika) refers to their emergence out of a sort of quantum entanglement (dependent co-arising) and their constantly changing nature due to everything being related to everything else. In this emergent universe, there are no Eigenstates, no fixed and recognizable identity, the dharmas (things) assumed to exist in separation being only a matter of conventional designation, a sort of socially generated intersubjective order of language: Proof of Convention (Vyavaharasiddhi).

Kashyap V. Vasavada, Associate and Full Professor of Physics, Indiana-Purdue Univ. Indianapolis, IN, and Visiting Professor, Cornell Univ. Ithaca, NY, is just one among a host of authors writing on the topic of Hindu sources of quantum theories, including contemporary developments, such as the search for the God particle or the hypothesis of a quantum consciousness:

I suspect there is an all pervading holistic non-local layer which we may call Brahman. Part of our consciousness may draw on this. This connection may be what is called Atman. Non-local entanglements of atoms may be also related to this layer. Local interactions which one sees in physics and also in everyday life may be superimposed on this. These are much more prevalent. The main point of this article is that somehow sensory and non sensory aspects of the universe agree. A complete answer to these puzzles will come when we understand consciousness and its relation to the nature at large (Vasavada: web).

The "master entity", the underlying entity of the universe, corresponds to the particle and forces unified by the theory of the bosonic string (Wray: web) which propagates in space and time. The string in spacetime maps out the worldsheet $X^{\mu}(\tau, \sigma)$, the two dimensional extension of the worldline for a particle, with $\tau$ being time-like and $\sigma$ being space-like.The solution to the field equations of the worldsheet is given by a linear combination of two arbitrary functions whose arguments depend only on one of the light-cone (past and future) coordinates, which, in the usual worldsheet coordinates, $\tau$ and $\sigma$, can be thought of as left and right moving waves, which propagate through space at the speed of light. The worldsheet with the $\tau$ and $\sigma$ coordinates 
separates into a linear combination of complementary functions, dependent upon $\tau-\sigma$ only, or $\tau$ $+\sigma$ only. The boson string (particles, including the Higgs God-boson, each with its pack of oscillations) may be said to simulate the movement of a particle along the worldline separating the past and future light-cones, with its pack of waves. In both cases, the vibrating ONE or master-entity, either of the Rig-Veda cosmogony or of Nagarjuna's dependent rising (emergence) may easily be identified.

There is a level of understanding which bespeaks, according to Niklas Luhmann, the stage reached by a civilization in its rise from nature to self-reflexivity. His last book, The Society of Society (Die Gesellschaft der Gesellschaft, 1997), defines the highest level of evolution as that of a culture's awareness of its own narratives. They are not the grand narratives of modernity (cult of reason and of science, trust in progress, the civilizing mission, etc.) but metanarratives: a recall of a community's history of ideas and their critical evaluation. In a highly developed society, discourses are not reflective of individual minds but connected to a higher order which is the communication system of society. According to Luhmann, societies evolve from an undeveloped ("segmented") to an evolved ("stratified") stage:

Luhmann analyzes historical societies according to their level of differentiation. In itselementary form, society is segmented. A segmented society is characterized by the functional uniformity of its parts: the form $\sim$ meaning, value, usefulness! of one segment is the same as the next. With increasing differentiation, the segmented society becomes stratified.

In a stratified society, the social meaning of a person extends from the class, estate, or caste to which he belongs. As the stratified society grows in influence and develops enduring trade relationships with segmented societies, its form becomes the difference between center and periphery. The society at the center $\sim$ Athens, Rome, London, etc.- is characterized by a stratification system, while the periphery remains segmented. Nonetheless, the structural ties that exist between the center and periphery facilitate communication. Finally, as the difference between center and periphery loses meaning due to assimilation and globalization, differentiation in society becomes functional. There is always only one "society of society," but there is no single functional society: There is an economic society, a political society, a religious society, an educational society, a military society, etc. Each societal system works at its own task, but each employs communication. As it evolves through these four stages, society expands and contracts with the constantly changing flow of actual communication. With greater differentiation, there is more communication. The more communication, the larger society becomes (Lee: 327-328).

The culture wars of the late 20 th century posed the question of center and periphery mainly in terms of deconstruction or relativization of an asymetric power relationship and in a postcolonial context. In counterdistinction, the early twenty-first century has seen the rise of border-crossing political entities and of multiculturalism, the increase in global communication and exchanges among members of an international academic community. In tracing the sources of contemporary epistemology to thinkers of the early twentieth century, and in taking a plunge into an affined ancient matrix of thought, the present paper has plumbed the virtual range of the humanities'expandind frontiers. 


\section{References}

Bachelard, Gaston. 1968 [1934]. Le nouvel esprit scientifique. Paris : Les Presses universitaires de France, 1oe edition.

http://classiques.uqac.ca/classiques/bachelard_gaston/nouvel_esprit_scientifique/nouvel_esprit.pdf

Bartholomae, David. 1986. "Inventing the University". Journal of Basic Writing, Vol. 5, No. 1. http://wac.colostate.edu/jbw/v5n1/bartholomae.pdf

Cassirer, Ernst. 1955 [1923]. The Philosophy of Symbolic Forms. Trans. Ralph Manheim. Preface and Introduction by Charles W. Hendel. New Haven and London: Yale University Press.

http://uberty.org/wp-content/uploads/2015/12/Ernst_Cassirer_The_Philosophy_of_Symbolic_Formsic.pdf

Heidegger, Martin. 1997 [1938]."The Age of the World Picture”. In Science and the Quest for Reality, ed. Alfred I. Tauber. London: Macmillan.

Heisenberg, Werner. 1958. Physics and Philosophy. The Revolution in Modern Science. London: George Allen and Unwin Ltd.

https://archive.org/stream/PhysicsPhilosophy/Heisenberg-PhysicsPhilosophy_djvu.txt

Lee, Daniel. 200o."The Society of Society: The Grand Finale of Niklas Luhmann" in Sociological Theory. Vol. 18, No. 2 (Jul., 2000), pp. 320-330

Park, Sowon S. 2015. "The Dilemma of Cognitive Literary Studies" in English Studies: The State of the Discipline, Past, Present, and Future, ed N. Gildea, H. Goodwyn, M. Kitching, H. Tyson, Aymo Brunetti. New York: Palgrave Macmilan.

Schrodinger, Erwin. 1944."What is life? The Physical Aspect of the Living Cell."Based on lectures delivered under the auspices of the Dublin Institute for Advanced Studies at Trinity College, Dublin, in February 1943.

http://selfdefinition.org/science/25-greatest-science-books-of-all-time/12.\%20Erwin\%2oSchrodinger\%20\%2oWhat\%2ois\%2oLife\%2o(1944).pdf

Snow C.P.[1959] 1961. The Two Cultures and the Scientific Revolution. New York: CUP.

http://sciencepolicy.colorado.edu/students/envs_5110/snow_1959.pdf

Vasavada, Kashyap V. 2012. "Modern Physics and Hindu Philosophy". https://grahamhancock.com/vasavadak2/

Wildgen, Wolfgang. 2004. "The phenomenology of symbolic forms (Cassirer) and geometrical reductionism (Klein, Leyton)". Winter-Symposium: Cognition and phenomenology. Philosophical implications of and preconditions for - the study of meaning, Aarhus Center for Semiotics, 29.-31.1.2004. http://www.fbı.uni-bremen.de/homepages/wildgen/pdf/phenomenology_symbolic_forms.pdf

Wray, Kevin. 2011. "An Introduction to String Theory".

https://math.berkeley.edu/ kwray/papers/string_theory.pdf

Maria-Ana Tupan is currently appointed to the Doctoral School of Alba Iulia University, Romania. From 1991 to 2014 Tupan taught courses in the history of British literature and in applied literary theory at Bucharest University. Member of The Romanian Writers Union, and of Die Gesellschaft für Fantastik Forschung. Author of 15 books, book chapters and articles published in Romania, Europe, and India. Papers read at conferences in Madrid, Manchester, Salzburg, Vienna, Dresden, Graz, Rome, Cologne. Awards from the Romanian Writers' Union and literary reviews. Publications in the fields of literary history and theory, comparative literature, genre theory, discourse analysis, and cultural studies. 